HETEROCYCLES, Vol. 95, No. 1, 2017, pp. 3-6. @ 2017 The Japan Institute of Heterocyclic Chemistry DOI: 10.3987/COM-16-S(S)Foreword_2

\title{
PREFACE TO HETEROCYCLES ISSUE HONORING THE 70TH BIRTHDAY OF PROFESSOR MASAKATSU SHIBASAKI
}

It is my great pleasure and honor to introduce this special issue of HETEROCYCLES in celebration of the 70th birthday of Professor Masakatsu Shibasaki, Emeritus Professor of Hokkaido University and The University of Tokyo, and currently Director of Institute of Microbial Chemistry. In Japanese tradition, Toshi-iwai is celebrated when a certain age is reached (such as 60,77,80, and 88), and Koki is celebrated at the age of 70 .

Professor Shibasaki's achievements have contributed enormously to the development of revolutionary multifunctional asymmetric catalysts, which have significantly advanced the field of asymmetric catalysis. These catalysts are utilized for the syntheses of various biologically active natural and unnatural compounds, including the spotlighted de novo synthesis of Tamiflu, and some are under extensive investigation for industrial-scale applications. In this preface, I would like to briefly review Professor Shibasaki's academic career and his great contributions to asymmetric catalysis, natural product synthesis, heterocyclic chemistry, and medicinal chemistry, among others, and I would also like to share with you some of my personal reminiscences as a long-time member of the "Shibasaki School".

Professor Shibasaki was born on January 25, 1947, in the Saitama Prefecture. In 1965, he entered The University of Tokyo and obtained his BS in 1969. In 1974 he was awarded his PhD from The University of Tokyo, Faculty of Pharmaceutical Sciences, working with Professor Shun-ichi Yamada. He then worked as a postdoctoral fellow from 1974 to 1977 in the research group of Prof. E. J. Corey at Harvard University to pursue the practical synthesis of natural products. He returned to Japan and began his academic career in 1977 as an associate professor at Teikyo University, where he synthesized various natural products, such as prostaglandins. In 1983, he moved to Sagami Chemical Research Center as a group leader, and in 1986, he accepted a professorship at Hokkaido University, where he gradually gravitated toward methodology development, especially asymmetric catalysis. In 1989, he revealed the first asymmetric Mizoroki-Heck reaction, which has not been subjected to asymmetrization attempts before his publication, using a desymmetrization strategy. Around that time, he became interested in the use of metal alkoxide as a Brønsted base catalyst, and these studies led to the discovery of multimetallic chiral complexes composed of a rare-earth metal, alkaline metals, and BINOLs, which made it possible to accomplish a number of unprecedented asymmetric reactions, such as the direct aldol reaction, in a highly efficient and stereoselective manner.

Professor Shibasaki returned to The University of Tokyo as a professor in 1991. At that time, I was a first-year master's degree student, and when I met him, he said to me, "Please think only of chemistry 
when you are in the lab." He first brought two graduate students from Hokkaido, and I began studying the asymmetric Heck reaction with them. Because there were only a few students pursuing his research at The University of Tokyo at that time, he would discuss our research with us everyday in front of the white board from evening until late at night. It was very tough time for a not-so-highly-motivated student like me, but looking back, it was a really valuable time for me and opened my eyes to the fun of chemistry. In the following year, several students moved from Hokkaido to Tokyo and new students also joined his group, so he constructed the efficient structure required for his research (photo 1). One of my best memories during that period was the elucidation of the very beautiful $C_{3}$-symmetric structure of the LLB complex by X-ray crystallographic analysis. After these revolutionary discoveries, his group developed a number of highly efficient multifunctional asymmetric catalysts that exert two or more catalytic functions to cooperatively activate two substrates (e.g., both electrophiles and nucleophiles) and offer an attractive activation manifold. We all worked very hard, but there was freedom in his group to conduct research according to our personal interests. When we produced excellent research results, he gave us a firm handshake while saying "Congratulations!" in his deep baritone voice.

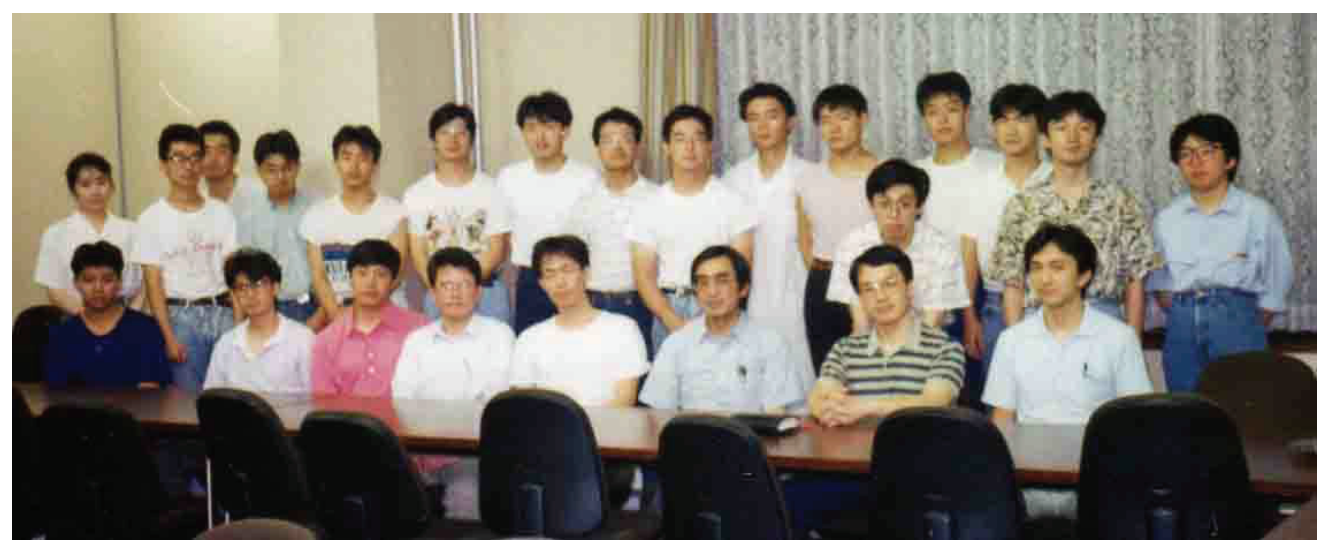

The concept of "multifunctionality" is now very popular in the field of catalysis, and his research group and others have developed a multitude of catalysts based on this concept. Professor Shibasaki's research group grew bigger and bigger, and many of excellent students sought to join his group. When I returned to his group as an assistant professor 3 years after obtaining my $\mathrm{PhD}$, it was one of the biggest and most energetic research groups in Japan and in the world. His research group developed many new multifunctional catalysts, such as Group 13/Group 1 bimetallic catalysts, two-center phase-transfer catalysts, bimetallic Schiff base catalysts, Lewis Acid/Lewis Base cooperative catalysts, and soft Lewis Acid/Brønsted Base cooperative catalysts, and achieved many total syntheses, including those of epothilones, strychnine, fostriecin, Tamiflu, Relenza, ranirestat, and caprazamycin. 
In 2010, at the age of 63 years, which is the designated retirement age at the university, he was appointed as the Director of the Institute of Microbial Chemistry and continues to actively work toward developing methods for asymmetric catalysis. One of his favorite words is "Zenryoku-Tokyu" (always give one's all in one's work). True to his word, he sustains enthusiasm for his research.

Professor Shibasaki's contributions to research have drawn worldwide acclaim, and he has received many prestigious awards. We would also like to express our appreciation to Professor Shibasaki for his continued efforts and contributions to academic societies, twice as the president of The Pharmaceutical Society of Japan (2006-2007 and 2014-2015) and also as the chairman of The 18th International Congress of Heterocyclic Chemistry (ICHC 2001) at Yokohama, Japan. He is an excellent educator, and his laboratory has produced many well-trained graduates - so far more than 50 of whom are actively working in academia.

Some people have said that they hesitate to speak to Professor Shibasaki at a conference because he has such a serious expression on his face. Of course, he is always serious about chemistry, but he is also a very considerate, caring, and charming person. Even when he was very busy, he spent an enormous amount of time listening to students' problems, not only with regard to their research, but also their personal lives. We often had jubilant drinking parties (photo 2) and went to "Karaoke" to sing songs. When he wanted to talk with us ASAP, he would indicate this in our notebooks with a special mark "maru-shiba" (photo 3). I often miss seeing this mark and my days working with him. Even now, he remains our "Big-Boss" and a father figure to his students. It was most welcome news to all of us that he stopped smoking a few years ago. We all wish him good health, happiness, and prosperity!
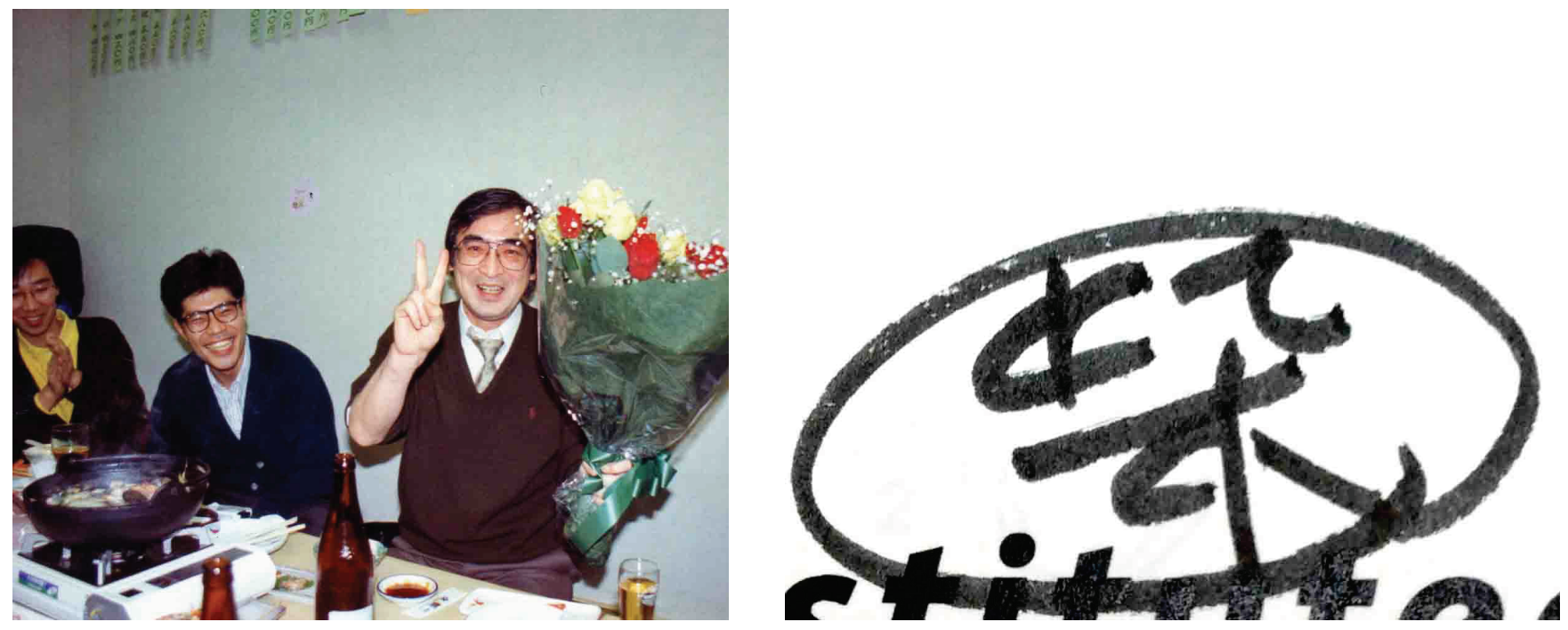


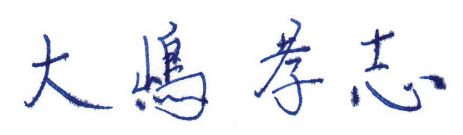

Takashi Ohshima

Professor of Graduate School of Pharmaceutical Sciences

Kyushu University

Fukuoka, Japan

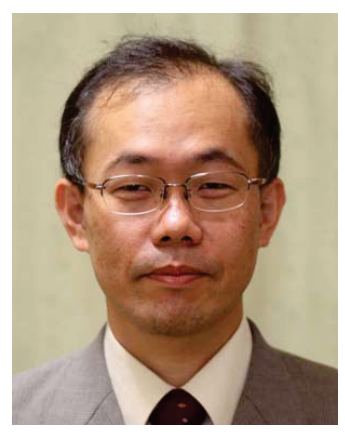

Takashi Ohshima was born in 1968 in Ehime, Japan. He received his bachelor's degree from The University of Tokyo in 1991 under the direction of Professor Masaji Ohno and received his PhD. degree from The University of Tokyo in 1996 under the direction of Professor Masakatsu Shibasaki. On the following year, he joined Otsuka Pharmaceutical Co., Ltd. for one year. After two years as a postdoctoral fellow at The Scripps Research Institute with Professor K. C. Nicolaou (1997-1999), he returned to Japan and joined Professor Shibasaki's group in The University of Tokyo as an assistant professor at Graduate School of Pharmaceutical Sciences. He was appointed as Associate Professor at Graduate School of Engineering Science, Osaka University in 2005. In 2010, he was promoted to full Professor at Graduate School of Pharmaceutical Sciences, Kyushu University. Currently, he is also vice-dean of Graduate School of Pharmaceutical Sciences and Professor of Greenpharma Research Center for System Drug Discovery. 